\title{
Addressing health literacy in patient decision aids
}

\author{
Kirsten J McCaffery ${ }^{1 *}$, Margaret Holmes-Rovner ${ }^{2}$, Sian K Smith ${ }^{3}$, David Rovner ${ }^{2}$, Don Nutbeam ${ }^{4}$, \\ Marla L Clayman ${ }^{5}$, Karen Kelly-Blake ${ }^{2}$, Michael S Wolf ${ }^{5}$, Stacey L Sheridan ${ }^{6}$ \\ From The International Patient Decision Aid Standards (IPDAS) Collaboration s Quality Dimensions: Theoretical \\ Rationales, Current Evidence, and Emerging Issues \\ Rockville, MD, USA. 13 September 2012
}

\begin{abstract}
Background: Effective use of a patient decision aid (PtDA) can be affected by the user's health literacy and the PtDA's characteristics. Systematic reviews of the relevant literature can guide PtDA developers to attend to the health literacy needs of patients. The reviews reported here aimed to assess:

1. a) the effects of health literacy / numeracy on selected decision-making outcomes, and b) the effects of interventions designed to mitigate the influence of lower health literacy on decision-making outcomes, and

2. the extent to which existing PtDAs a) account for health literacy, and b) are tested in lower health literacy populations.
\end{abstract}

Methods: We reviewed literature for evidence relevant to these two aims. When high-quality systematic reviews existed, we summarized their evidence. When reviews were unavailable, we conducted our own systematic reviews.

Results: Aim 1: In an existing systematic review of PtDA trials, lower health literacy was associated with lower patient health knowledge (14 of 16 eligible studies). Fourteen studies reported practical design strategies to improve knowledge for lower health literacy patients. In our own systematic review, no studies reported on values clarity per se, but in 2 lower health literacy was related to higher decisional uncertainty and regret. Lower health literacy was associated with less desire for involvement in 3 studies, less question-asking in 2, and less patientcentered communication in 4 studies; its effects on other measures of patient involvement were mixed. Only one study assessed the effects of a health literacy intervention on outcomes; it showed that using video to improve the salience of health states reduced decisional uncertainty. Aim 2: In our review of 97 trials, only 3 PtDAs overtly addressed the needs of lower health literacy users. In 90\% of trials, user health literacy and readability of the PtDA were not reported. However, increases in knowledge and informed choice were reported in those studies in which health literacy needs were addressed.

Conclusion: Lower health literacy affects key decision-making outcomes, but few existing PtDAs have addressed the needs of lower health literacy users. The specific effects of PtDAs designed to mitigate the influence of low health literacy are unknown. More attention to the needs of patients with lower health literacy is indicated, to ensure that PtDAs are appropriate for lower as well as higher health literacy patients.

\section{Background}

A person's health literacy status affects their ability to utilise health information and services, and their health outcomes [1]. It is therefore an important potential consideration in patient decision aid (PtDA) development and shared decision making $[2,3]$. There has been no

\footnotetext{
* Correspondence: kirsten.mccaffery@sydney.edu.au

'Sydney School of Public Health, Sydney Medical School, Edward Ford

Building (A27), The University of Sydney, NSW 2006, Australia

Full list of author information is available at the end of the article
}

systematic examination of the effects of health literacy on outcomes relevant to PtDA development or of interventions that might mitigate potential adverse effects of low health literacy in the decision-making context.

Health literacy can be conceptualized in different ways. A simple and common definition is "the capacity to obtain, process, and understand basic health information and services needed to make appropriate health decisions" $[4,5]$. However, broader definitions are gaining popularity and encompass a wider range of cognitive and social
C Biomed Central

C 2013 McCaffery et al; licensee BioMed Central Ltd. This is an Open Access article distributed under the terms of the Creative Commons Attribution License (http://creativecommons.org/licenses/by/2.0), which permits unrestricted use, distribution, and reproduction in any medium, provided the original work is properly cited. 
skills that enable people to feel empowered to take control and improve their health [6,7]. Nutbeam's model of health literacy delineates three levels $[7,8]$ :

1. Functional health literacy - basic reading comprehension and writing skills to understand health information/messages, together with knowledge of health conditions, services, and systems.

2. Communicative/interactive health literacy - higher level communicative and social skills required to extract and discuss information with others.

3. Critical health literacy skills - advanced literacy, cognitive, and social skills to analyze information and make informed decisions.

We propose that these levels correspond with the skills required to effectively use PtDAs and to engage in shared decision making activities: understanding health information, clarifying personal values, and communicating with health care providers.

A high proportion of adults have limited health literacy. In the U.S., estimates suggest that 36\% (80 million adults) have "basic" or "below basic" health literacy [9]. Although methods of assessment vary, the picture is very similar in other developed countries [10]. The high levels of limited health literacy throughout the world provide a sharp reminder of the need to provide health information in a form that is appropriate for the literacy and numeracy levels of the majority of adults for whom it is prepared.

A person's ability to effectively use a PtDA will be determined by both their health literacy skills and the quality and suitability of the PtDA [2]. Designers of PtDAs need to ensure that their tools can be accessed and understood by adults across the health literacy spectrum, including those with lower health literacy, and can support decisions that are both informed and behaviorally implemented.

\section{Theoretical justification for addressing health literacy in patient decision aids}

We propose that Nutbeam's multi-level model of health literacy provides a useful framework to help PtDA developers to address the needs of lower health literacy patients. Each of the levels of health literacy described in the model provides the skills required by patients to effectively use PtDAs and to engage in shared decision making. Individuals can obtain differential benefit from PtDAs depending on the relative differences in their health literacy. Those with the most basic functional health literacy will be able to obtain information from a PtDA and to use this as the basis for a more informed decision about their health. Those with higher level skills will be able to make greater use of available information to consider critically what is best for them, and to interact and communicate successfully with their health care provider in making a shared decision.
Attending to each of the levels of health literacy in PtDA design is important in order to meet the needs of patients with lower health literacy. This means developing PtDA materials to support consumers not only to read and understand evidence-based information (i.e., functional health literacy), but also to have the skills and confidence to communicate with health professionals and negotiate decisions (interactive/ communicative health literacy), and to clarify their values and think critically to make an informed decision (critical health literacy).

\section{Purpose and objectives}

This paper systematically reviews the literature to guide PtDA developers as they attend to the health literacy needs of patients. We systematically reviewed empirical evidence relevant to health literacy and PtDAs with two principal aims:

I. To assess a) the effects of health literacy / numeracy on selected decision-making outcomes, and b) the effects of interventions designed to mitigate the influence of lower health literacy on decision-making outcomes, and

II. To assess the extent to which existing PtDAs a) account for health literacy, and b) are tested in lower health literacy populations.

\section{Empirical evidence: two reviews}

REVIEW I. Health literacy / health numeracy: the effects on decision-making outcomes and the effects of health literacy interventions

To address our first aim, we asked two review questions: 1) What is known about how health literacy affects decision-making outcomes, including knowledge, values clarity, and patient involvement? and 2) What is known about health literacy interventions' ability to mitigate the effects of lower health literacy on decision-making outcomes?

\section{Review I: overview of methods}

We searched two existing systematic reviews conducted for the U.S. Agency for Healthcare Research and Quality (AHRQ) in 2004 and 2011 on Health Literacy Interventions and Outcomes $[1,11]$ for answers to these questions, and summarized their results if they were available. When questions were not answered (e.g., for outcomes and health literacy interventions related to values clarity or to patient involvement in decision making and communication (see below)), we performed our own systematic review and data synthesis.

\section{Review I: data sources and selection}

To identify relevant articles, we searched articles included in the 2004 and 2011 systematic reviews performed for the 
AHRQ. These reviews had examined 1) the effects of health literacy (including numeracy) on health outcomes, and 2) the effects of interventions designed to mitigate the effects of low health literacy on health outcomes. These reviews had focused on English-language articles with an objective measure of health literacy that were published from 1966 to February 2011 and indexed in MEDLINE ${ }^{\circledR}$, CINAHL, PsycINFO, ERIC, or the Cochrane Library database, and used the keywords literacy, numeracy, or terms or phrases related to measures thereof [1,11-13].

For our review, we also searched the titles and abstracts of articles that had been excluded from the 2011 AHRQ review [1] for the following reasons: 1) they didn't use an objective measure of health literacy, or 2) they used an objective measure of health literacy, but reported only on outcomes that were not of interest to the AHRQ review (including outcomes related to clarifying values and participating in decision making). We did not search articles that had been excluded from the 2004 review [11] because they predated landmark work in health literacy [4] and the first set of International Patient Decision Aid Standards (IPDAS) that called for values clarification and coaching as components of decision making [3].

To determine article inclusion, first one reviewer adhered to the inclusion criteria listed in Table 1, and excluded articles that were clearly unrelated to the questions guiding our review. Two reviewers then reviewed the remaining abstracts, and when necessary, reviewed full text articles to determine inclusion. Reviewers also reviewed the reference lists of included studies, prior narrative reviews on health literacy and decision making
[2] or communication [14], and the bibliographies of systematic reviews on question-asking [15] and patientcentered care [16].

The inclusion criteria for this review mirrored the criteria used in the AHRQ reviews. However, our criteria were extended to include articles that included individual-level subjective assessments of health literacy, as well as outcomes related to clarifying values (e.g., decision uncertainty, decision regret, decision confidence, values clarity) and outcomes related to participating in decision making during the clinical encounter (e.g., patient activation, desire to participate, actual participation, communication quality). Our selection of these decision outcomes was guided by the general functional goals of PtDAs [17], which are: 1) To support users to understand health information relevant to their decision; 2) To support users to clarify their values; and 3) To support users to be actively involved in decision making and to communicate with others. Thus, these functional goals served as an overall conceptual structure for our review, as outlined in Table 2 .

\section{Review I: data extraction and quality assessment}

After inclusion was determined, a single reviewer entered information about studies into evidence tables, and a second reviewer checked abstractions for accuracy and consistency in presentation. Two reviewers independently rated study quality (good, fair, poor), using quality forms developed for the AHRQ reviews [1]. These forms assessed selection bias, measurement bias, confounding, and inadequate power. We excluded poor quality studies from our analysis and resolved disagreements about

Table 1 Inclusion Criteria for Review I

\begin{tabular}{|c|c|}
\hline Inclusion Category & Inclusion Criteria \\
\hline Study Population & $\begin{array}{l}\text { All ages, races, ethnicities, and cultural groups in developed countries. } \\
\text { Health literacy and numeracy levels of individuals are either objectively or subjectively measured and reported for } \\
\text { individuals in the population. }\end{array}$ \\
\hline Health Outcomes & $\begin{array}{l}\text { Includes decision-making outcome of interest: } \\
\text { Values clarity } \\
\text { Decision certainty } \\
\text { Decision regret } \\
\text { Decision confidence } \\
\text { Desire for participation in decision } \\
\text { Question asking } \\
\text { Actual participation in decision } \\
\text { Communication quality } \\
\text { - Information provision/receipt } \\
\text { - Good processes of communication/care } \\
\text { - Satisfaction with communication/decision/care }\end{array}$ \\
\hline $\begin{array}{l}\text { Health Literacy } \\
\text { Intervention }\end{array}$ & Interventions that authors report are specifically designed to mitigate the effects of low health literacy. \\
\hline Study Design & $\begin{array}{l}\text { Cross-sectional and cohort studies of the effects of health literacy and numeracy on decision making outcomes. } \\
\text { Experimental studies of the effects of interventions on health outcomes. }\end{array}$ \\
\hline Study Analyses & Stratified by Health Literacy Level with levels for analysis clearly specified. \\
\hline Publication Status & Peer-reviewed articles. English language. \\
\hline
\end{tabular}


Table 2 Conceptual Structure for Review I: Three Function Goals of PtDAs

\begin{tabular}{ll}
\hline \multicolumn{1}{c}{ Function goals } & \multicolumn{1}{c}{ Relevant literature included in first review } \\
\hline $\begin{array}{l}\text { PtDA Goal 1: To support users to understand health } \\
\text { information relevant to their decision. }\end{array}$ & $\begin{array}{l}\text { a) Articles relating to knowledge or understanding of health information included in } \\
\text { AHRQ reviews } 2004 \text { and } 2011 \text { [1,11]. } \\
\text { b) Articles relating to interventions designed to improve these outcomes in } \\
\text { individuals with low health literacy. }\end{array}$ \\
\hline PtDA Goal 2: To support users to clarify their values. & $\begin{array}{l}\text { a) Articles relating to patients' health values clarification, preference formation, } \\
\text { uncertainty, decision satisfaction, decisional conflict and decisional regret. }\end{array}$ \\
\hline $\begin{array}{l}\text { b) Articles relating to interventions designed to improve these outcomes in } \\
\text { individuals with low health literacy. }\end{array}$ \\
$\begin{array}{ll}\text { decision making and to communicate with others. } & \begin{array}{l}\text { a) Articles relating to patient involvement and preferences for involvement in } \\
\text { decision making, patient activation, patient question asking, patient centered }\end{array} \\
\text { consultations and doctor-patient communication }\end{array}$ \\
$\begin{array}{l}\text { b) Articles relating to interventions designed to improve these outcomes in } \\
\text { individuals with low literacy. }\end{array}$
\end{tabular}

inclusion by consensus. Figure 1 is a flow diagram summarizing the full process of article exclusion / inclusion.

\section{Review I: data synthesis}

Given the diversity in study outcomes and measurements, we synthesized data qualitatively and not by meta-analysis. We divided studies into those addressing values clarity and those addressing patient involvement and communication.

\section{Review I: results}

Below, the results for the first review are structured according to three general functional goals of PtDAs [17]. Detailed summary tables for this first review appear in Appendices 1 to 4 (see Additional files 1, 2, 3, 4).

PtDA Goal 1: To support users to understand health information relevant to their decision

The two AHRQ reviews addressed our questions related to health literacy / numeracy, knowledge outcomes, and health literacy interventions. Their findings are summarized below, grouped according to our two review questions. Relationship between health literacy / numeracy and the outcomes of knowledge, comprehension, and risk perception The 2004 AHRQ review found that low health literacy (measured predominantly by the Rapid Estimate of Adult Literacy in Medicine (REALM) or Test of Functional Health Literacy in Adults (TOFHLA)) was related to patient knowledge in 14 of 16 studies dating from 1980 through 2003 [11]. Of the two studies that did not show a relationship, one was underpowered. Investigators concluded that the relationship was so clear that additional examination of this relationship was not necessary during a 2011 update.

The 2011 AHRQ review assessed the effect of numeracy on knowledge and on accuracy of risk perception from 1966 to February 2011 [1]. In four studies with a quantitative measure of numeracy, investigators found mixed effects of numeracy on general and disease-specific knowledge. Additionally, in five studies with a quantitative measure of numeracy, investigators found mixed effects of numeracy on the accuracy of perception of absolute risk and treatment benefit (expressed in multiple formats, including relative risk reduction (RRR), absolute risk reduction (ARR), or number needed to treat (NNT), with notable variations by task and measured outcomes (e.g., disparities in accuracy were even greater for participants when stating exact benefit rather than comparing the benefit of two treatments).

Effect of health literacy interventions designed to help low literacy individuals' knowledge, comprehension, or accuracy of risk perception A paper published from the 2011 AHRQ review that included an updated search [13] identified 38 studies published between 1966 and February 2011 that met the following criteria: they examined the effect of single or multiple literacy-directed strategies on knowledge or comprehension; they quantitatively assessed participants' health literacy or numeracy; and they stratified analyses by health literacy level.

Fourteen of these studies (13 RCTs and 1 non-randomized controlled trial) specifically examined the effects of single strategies that might be useful in PtDA design. Among these 14 studies (which were reported in 12 articles) [18-29], investigators found multiple discrete design features that improved comprehension for low health literacy individuals in at least one study. These are summarized in Table 3. Of the remaining 24 studies that reported on interventions using a mixture of literacy-directed strategies, only one reported on a health literacy intervention in a PtDA context [30]. While this pre-post study of a prostate cancer PtDA reported improved knowledge among individuals in all health literacy subgroups (adequate literacy: +1.27 points on a 10 -point scale, adjusted $p<0.01$; inadequate literacy +2.05 points, adjusted $p<0.01 ; p$ for interaction not reported), it did not describe its literacy-directed strategies in sufficient detail to allow recommendations to be derived. 


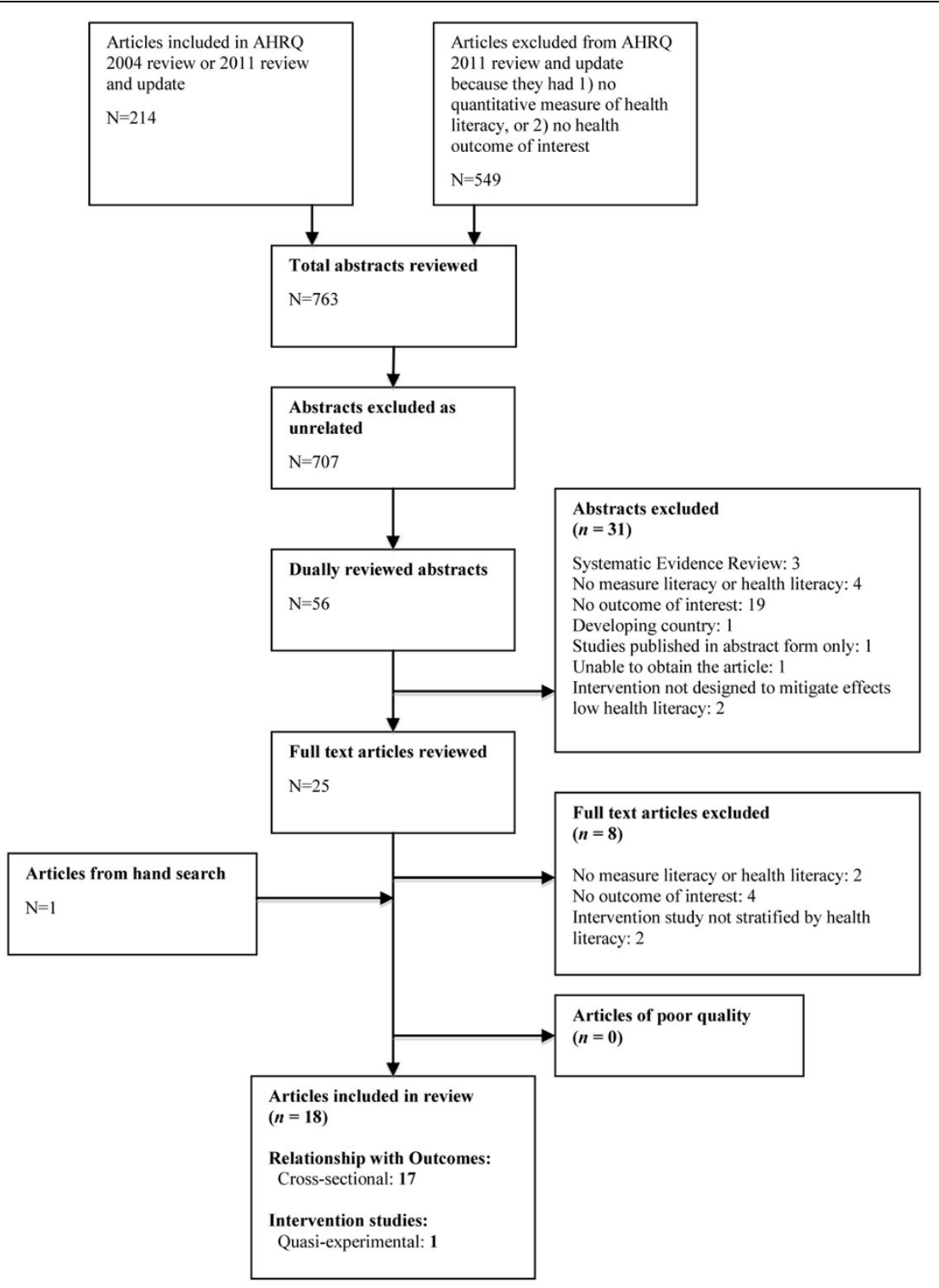

Figure 1 Flow Diagram for Inclusion / Exclusion of Articles in Review I

PtDA Goal 2: To support users to clarify their values

In our own systematic review, we addressed the relationship between health literacy / numeracy and the outcome of values clarity, and the effect of health literacy interventions on values clarity.
Relationship between health literacy / numeracy and the outcome of values clarity We found no studies that examined the relationship between health literacy and values clarity per se. Four cross-sectional studies [31] investigated the relationships between health literacy

Table 3 Partial Summary of Review I Findings Relative to PtDA Goal 1: to support users to understand health information relevant to their decision

Health Information Design Features that Improved Comprehension for Lower Health Literacy Individuals in at Least One Study

- Presenting essential information by itself or first [25]

- Presenting numerical information in tables or pictographs rather than text $[19,21,26]$

- Presenting numerical information so that the higher number is better (i.e. "nurses per patient"(more is better) rather than "patients per nurse" (less is better)) [25]

- Presenting numerical information with the same denominator [21]

- Using natural frequencies (e.g. 1 out of 100) to help individuals understand the probability of disease following testing [20]

- Adding video to verbal narratives to improve the salience of information about health states [27] 
and decision uncertainty, decisional regret, and decision confidence. In the two studies that performed adjusted analyses, lower subjective health literacy increased decision uncertainty [31-34], and lower objective health literacy increased decision regret [32]. The effect of health literacy on decision confidence is less clear, with two unadjusted analyses showing mixed results [33,34]. See Table 4.

Effect of health literacy interventions designed to help low literacy individuals clarify values In the single intervention study in this group [35], Volandes et al. found that a PtDA using videos of patients to help elucidate the salience of various health states reduced decision uncertainty among all patients, with the greatest reduction found among patients with lower objective health literacy. See Table 4.

PtDA Goal 3: To support users to be actively involved in decision making and to communicate with others

In our own systematic review, we addressed the relationship between health literacy / numeracy and the outcomes of patient involvement and communication, and the effect of health literacy interventions on patient involvement and communication. See Table 5.

Relationship between health literacy / numeracy and the outcomes of patient involvement and communication Thirteen studies reviewed the relationship between health literacy level and various aspects of the decision-making encounter, such as patient activation and desire for participation, question-asking, broader participation, and communication quality. Three studies, including two that adjusted for confounders, reported that adults with lower health literacy were less likely to want to be involved in decision making compared to those with higher literacy [36-38]. A fourth showed that patient activation was associated with numeracy, but not health literacy in unadjusted correlational analysis [39].

Two papers addressed the relationship between literacy and question-asking $[40,41]$. One found that both level and type of subjective health literacy (functional, communicative, or critical) influenced question-asking, with lower levels of communicative health literacy associated with less question-asking [40]. The other found that lower objective health literacy patients were less likely to ask questions overall (although this just failed to reach statistical significance) [41] . Of the questions asked, lower health literacy patients asked significantly fewer medical and lifestyle questions and more clarification questions suggesting lack of understanding.

Two papers addressed patient involvement more broadly. One study reported patients with lower subjective "communicative" health literacy perceived they had less involvement in clinical consultations (although this just failed to achieve statistical significance, likely due to the small sample size) [40]. Arthur et al. reported a trend toward less "mutuality" (where both the physician and patient displayed a shared role in deciding the patient's healthcare plan) among U.S. diabetes patients with limited objective health literacy [42].

Of the nine studies examining communication quality, four large high-quality studies with adjusted analyses reported lower patient-centered communication across several communication outcomes among those with lower objective health literacy $(n=2)$, lower subjective health literacy $(\mathrm{n}=1)$, and lower subjective numeracy $(\mathrm{n}=1)$. Communication was not specific to decision making, and the effect varied by outcome [43-46]. A fifth study, in which the sample overlaps with one of the previous four, found that ratings of patient-centered communication varied by measurement of numeracy. Patients with low objective numeracy reported more favorable communication and those with low subjective numeracy reported less favorable communication [47]. One unadjusted analysis found no difference between lower and higher health literacy patients' perceptions that doctors facilitated their involvement in diabetes care [36].

Results of the remaining three studies varied by outcome. One study found that parents with lower objective

Table 4 Summary of Review I Findings Relative to PtDA Goal 2: to support values clarification among lower literacy consumers

\begin{tabular}{ccc}
\hline & Effect of health literacy on values clarification \\
\hline & $\begin{array}{c}\text { No. of } \\
\text { Studies }\end{array}$ & Summary of Findings \\
\hline $\begin{array}{c}\text { Decisional uncertainty } \\
\text { Decisional regret } \\
\begin{array}{c}\text { Confidence in decision } \\
\text { making }\end{array}\end{array}$ & $2[31,32]$ & Lower health literacy associated with higher uncertainty and decisional regret. \\
& $2[33,34]$ & Effect unclear. \\
\hline & $\begin{array}{c}\text { No. of } \\
\text { Studies }\end{array}$ & Summary of Findings \\
\hline Decisional uncertainty & $1[35]$ & $\begin{array}{l}\text { Video images to increase the salience of health states reduced decisional uncertainty, with strongest } \\
\text { effect in lower health literacy patients. }\end{array}$ \\
\hline
\end{tabular}


Table 5 Summary of Review I Findings Relative to PtDA Goal 3: to support patient involvement and communication among lower literacy consumers

\begin{tabular}{|c|c|c|}
\hline \multicolumn{3}{|c|}{ Effect of health literacy on involvement and communication } \\
\hline & No. of Studies & Summary of Findings \\
\hline \multirow{2}{*}{$\begin{array}{l}\text { Preferences for participation in decision } \\
\text { making / patient activation }\end{array}$} & $3[36-38]$ & Lower preference for involvement among lower health literacy patients. \\
\hline & $1[39]$ & Patient activation associated with lower numeracy not health literacy. \\
\hline Question asking & $2[40,41]$ & $\begin{array}{l}\text { Less question asking among those with lower communicative HL. More clarification } \\
\text { questions asked (indicating lack of understanding) }\end{array}$ \\
\hline Level of involvement & $2[40,42]$ & $\begin{array}{l}\text { Patients with lower communicative health literacy reported less involvement. Less } \\
\text { mutuality observed between doctors and lower health literacy patients }\end{array}$ \\
\hline \multirow[t]{2}{*}{$\begin{array}{l}\text { Communication quality / Patient } \\
\text { centered care }\end{array}$} & $\begin{array}{c}6 \\
{[36,43,44,46-48]}\end{array}$ & $\begin{array}{l}\text { Less patient centered care among lower health literacy patients in } 5 \text { studies with } \\
\text { adjusted analyses. } 1 \text { study reported effects varied by how numeracy was measured. }\end{array}$ \\
\hline & $3[31,40,48]$ & Effects on communication quality (satisfaction and perceived quality) varied. \\
\hline \multicolumn{3}{|c|}{ Effect of health literacy intervention studies on involvement and communication } \\
\hline & No. of Studies & Summary of Findings \\
\hline & None & Not applicable \\
\hline
\end{tabular}

health literacy reported more favorable interactions with their child's healthcare provider [48]. Another found poorer decision satisfaction about breast cancer treatment among those with lower subjective health literacy [31]. Finally, one study found that those with lower critical health literacy were more likely to report they had received adequate information when more information was given (whereas those with higher critical literacy did not), offering a potential explanation for the contrasting findings reported above [40].

Effect of health literacy interventions designed to help low literacy individuals with communication We identified no papers that tested health literacy interventions to assist the communication in the encounter, although one reported on the design of a cluster randomized trial to aid communication [49].

\section{Review II. Attending to health literacy among lower literacy populations in PtDA trials}

To address our second aim, we asked the question: what level of attention is paid to health literacy in trials of PtDAs to date?

\section{Review II: overview of methods}

To assess how health literacy has been addressed in PtDA trials, we systematically examined the PtDAs included in the published Cochrane Collaboration review of randomized controlled trials of PtDAs (including trials published to the end of 2009) [50]. We additionally updated their review with studies published to the end of 2010 (identified using the same search strategy).

\section{Review II: data sources}

To identify articles, we used a set of 102 references maintained by the Cochrane Decision Aid group that included reports of 97 separate decision aids. This list is an up-to-date listing complete through to the end of 2010. We note that $16 / 102$ papers published in 2010 and reporting on 11 decision aids were identified with the assistance of the Cochrane Group and added to the current review. These have not been included in published reports of the main Cochrane Collaboration's systematic review of decision aids [50].

\section{Review II: data selection}

After discussion among the 3 members of the review team, a set of review criteria was developed to indicate reading level accessibility to lower literacy audience and attention to literacy in the research design. The evaluative criteria for this review were based on those published in the 2006 IPDAS for literacy standards in PtDAs (see Table 6), with five new review criteria added to assess the level of attention paid to health literacy in the trials design (items 4-8 in Table 6).

Each study was graded using these eight review criteria. Criteria were coded as present, absent, or unknown. Lack of indication of meeting any of the original IPDAS literacy criteria and lack of mention of health literacy at all were coded as "absent". If articles made a global reference to the IPDAS literacy criteria, but made no specific mention of the particular IPDAS literacy criteria addressed, they were scored as "unknown". See Table 7 for the working definitions of our full set of eight criteria and an explanation of how coding was performed. Additional detail about Review II's criteria is available in Additional file 5 Appendix 5.

We found that the original IPDAS literacy criterion \#1 ("decision aid written at a level that can be understood by a majority of the sample") to be very hard to determine. The intent of the criterion was that the PtDA developers should state the literacy requirements of the population for whom the PtDA was intended. The criterion was 


\section{Table 6 Eight Criteria used in Review II to Assess PtDAs' Reading Level Accessibility and PtDA Trials' Attention to} Literacy

\begin{tabular}{ll}
\hline Original IPDAS Literacy Criteria \\
\hline 1 & Is the PtDA written at a level that can be understood by the majority of patients in the target group? \\
2 & Is the PtDA written at a grade 8 or equivalent level or less according to readability score [SMOG or FRY]? \\
3 & Does the PtDA provide ways to help patients understand information other than reading [audio, video, in-person]? \\
PtDA Trial Design Criteria \\
\hline 4 & Was the PtDA web-based? \\
5 & Were study groups stratified by literacy? \\
6 & Were study groups stratified by education? \\
7 & Were low literacy groups over-sampled? \\
8 & Were any conclusions drawn regarding literacy? (If yes, what?) \\
\hline
\end{tabular}

meant to encourage matching of population literacy requirements to the tool developed. However, in practice, the population literacy requirements were never stated, though sometimes the literacy level of the specific study sample was evaluated. To credit the attention paid by some investigators to the literacy levels of the sample, without having to attribute attention to population literacy requirements, we modified the wording of this criterion to code if literacy requirements of the subjects of the research were stated.

To test the functionality of our set of criteria, a $13 \%$ random sample was drawn from the pre-2010 set of 85 PtDAs, and assigned to 3 reviewers in groups of two in a blinded manner. One of us compared ratings and found that there was disagreement in $5.6 \%$ of the ratings. There were no obvious differences among the 3 reviewers in accuracy. We then discussed the differences and better specified the definitions.

\section{Review II: results}

The total number of PtDA trials in the latest Cochrane update was 86. Eleven more trials were identified in the updated search through 2010, so that the total set of PtDA trials evaluated was 97 [50]. Table 8 lists the percentages and absolute numbers of individual studies that were evaluated according to our set of literacy criteria.

Table 7 Eight Criteria used in Review II to Assess PtDAs and PtDA Trials: Their Definitions and Coding Values

\begin{tabular}{|c|c|c|c|}
\hline & Criterion Tag and Definition & Coding Value & Notes \\
\hline 1 & $\begin{array}{l}\text { Lit Level Understood } \\
\text { Is the PtDA written at a level that can be understood by a majority of patients in the study } \\
\text { sample? If no mention of measuring comprehension was made a "2" was assigned. A simple } \\
\text { increase in knowledge by the subjects was not taken to mean they understood. }\end{array}$ & $\begin{array}{l}\text { Yes }=1 \\
\text { No }=2\end{array}$ & \\
\hline 2 & $\begin{array}{l}<\text { Grade } 9 \\
\text { Was the PtDA stated to be at grade } 9 \text { readability level or less? }\end{array}$ & $\begin{array}{l}\text { Yes }=1 \\
\text { No }=2 \\
\text { Don't know }=9\end{array}$ & $\begin{array}{l}\text { If yes, what } \\
\text { measure? }\end{array}$ \\
\hline 3 & $\begin{array}{l}\text { Other than Text } \\
\text { Does the PtDA provide ways to help patients understand information other than by reading? } \\
\text { Includes specifically audio, video, web-based or reading aloud by researcher. }\end{array}$ & $\begin{array}{l}\text { Yes }=1 \\
\text { No }=2 \\
\text { Don't know }=9\end{array}$ & $\begin{array}{l}\text { If yes, what } \\
\text { medium/media? }\end{array}$ \\
\hline 4 & $\begin{array}{l}\text { Web-based } \\
\text { The web is understood to mean access by computer, either at home or some other location with } \\
\text { access to the world wide web. } \\
1=\text { web-based and not all text; } 2=\text { not web-based; } 3=\text { web-based and all text; } 9=\text { web-based } \\
\text { and couldn't tell whether all text-based or not. } \\
\text { (If } 2 \text {, then not web; if } 1 \text { or } 3 \text { or } 9 \text {, then web-based.) }\end{array}$ & $\begin{array}{l}1=\text { multimedia web } \\
2=\text { no web } \\
3=\text { web text } \\
9=\text { web but couldn't } \\
\text { tell content }\end{array}$ & \\
\hline 5 & $\begin{array}{l}\text { Stratified by Literacy } \\
\text { Was the study sample stratified by literacy level? }\end{array}$ & $\begin{array}{l}\text { Yes }=1 \\
\text { No }=2 \\
\text { Don't know }=9\end{array}$ & $\begin{array}{l}\text { If surrogate } \\
\text { measure, what? }\end{array}$ \\
\hline 6 & $\begin{array}{l}\text { Stratified by Education } \\
\text { Was the study sample stratified by education level? }\end{array}$ & $\begin{array}{l}\text { Yes }=1 \\
\text { No }=2 \\
\text { Don't know }=9\end{array}$ & $\begin{array}{l}\text { If surrogate } \\
\text { measure, what? }\end{array}$ \\
\hline 7 & $\begin{array}{l}\text { Over -sampled Lower Literacy? } \\
\text { Did the study over-sample lower literacy populations? }\end{array}$ & $\begin{array}{l}\text { Yes }=1 \\
\text { No }=2 \\
\text { Don't know }=9\end{array}$ & \\
\hline 8 & $\begin{array}{l}\text { Literacy Conclusion? } \\
\text { Did the study draw literacy conclusions? (Code }=1 \text { if any mention of literacy effects upon outcome } \\
\text { variables, including if subgroup analyses were undertaken post-hoc) }\end{array}$ & $\begin{array}{l}\text { Yes }=1 \\
\text { No }=2 \\
\text { Don't know }=9\end{array}$ & If yes, what? \\
\hline
\end{tabular}


Table 8 Review II's Summary of Attention Paid to Health Literacy in PtDA Trials

\begin{tabular}{|c|c|c|c|c|c|c|c|c|}
\hline \multicolumn{9}{|c|}{ Criteria Used to Evaluate PtDA Trials \% (n) } \\
\hline & $\begin{array}{c}\text { Literacy } \\
\text { Level Stated }^{\dagger}\end{array}$ & $\begin{array}{c}\leq \text { Grade } 8 \\
\text { Reading Age }\end{array}$ & $\begin{array}{l}\text { Media other } \\
\text { than Text }^{+\dagger}\end{array}$ & $\begin{array}{l}\text { Web- } \\
\text { Based }\end{array}$ & $\begin{array}{l}\text { Stratified by } \\
\text { Literacy }\end{array}$ & $\begin{array}{l}\text { Stratified by } \\
\text { Education }\end{array}$ & $\begin{array}{l}\text { Lower Literacy } \\
\text { Over-Sampled }\end{array}$ & $\begin{array}{l}\text { Literacy Addressed } \\
\text { in Conclusion }\end{array}$ \\
\hline Present & $\begin{array}{c}4 \\
(4)\end{array}$ & $\begin{array}{c}5 \\
(5)\end{array}$ & $\begin{array}{l}68 \\
(67)\end{array}$ & $\begin{array}{c}3 \\
(3)\end{array}$ & $\begin{array}{l}2 \\
(2)\end{array}$ & $\begin{array}{c}0 \\
0 \\
(0)\end{array}$ & $\begin{array}{l}2 \\
(2)\end{array}$ & $\begin{array}{c}3 \\
(3)\end{array}$ \\
\hline Absent & $\begin{array}{l}93 \\
(91)\end{array}$ & $\begin{array}{l}92 \\
(89)\end{array}$ & $\begin{array}{l}30 \\
(29)\end{array}$ & $\begin{array}{l}97 \\
(94)\end{array}$ & $\begin{array}{l}98 \\
(95)\end{array}$ & $\begin{array}{l}100 \\
(97)\end{array}$ & $\begin{array}{c}98 \\
(95)\end{array}$ & $\begin{array}{l}96 \\
(94)\end{array}$ \\
\hline Unknown & $\begin{array}{c}1 \\
(2)\end{array}$ & $\begin{array}{l}3 \\
(3)\end{array}$ & $\begin{array}{c}1 \\
(1)\end{array}$ & $\begin{array}{c}0 \\
(0)\end{array}$ & $\begin{array}{c}0 \\
(0)\end{array}$ & $\begin{array}{c}0 \\
(0)\end{array}$ & $\begin{array}{c}0 \\
(0)\end{array}$ & $\begin{array}{c}0 \\
(0)\end{array}$ \\
\hline Total & $100 \%$ & $100 \%$ & $100 \%$ & $100 \%$ & $100 \%$ & $100 \%$ & $100 \%$ & $100 \%$ \\
\hline Trials & (97) & (97) & (97) & (97) & (97) & (97) & (97) & (97) \\
\hline
\end{tabular}

${ }^{\top}$ Most trials did not identify the literacy level of the intended audience. We operationalized this criterion to code "present" if the research sample group's literacy requirements were stated.

${ }^{+\top}$ If the PtDA was text based, but included graphics of frequencies and other numeric data, these were considered to be text. This criterion was meant to provide for alternative media for non-readers such as pictures, video explanations of data, voice-over narration, etc.

Five of the 97 RCTs reported the PtDA reading level as grade 8 or below [51-55]. Two trial reports stated that IPDAS literacy criteria were followed, but made no reference to which specific criteria $[56,57]$. Many PtDAs used media other than pure text, including interactive video and audio tape, although it was not clear whether these modalities were used specifically to address issues of literacy. There were eight PtDAs available on the web, though in many the presence or absence of content other than straight text could not be determined [58-66].

Seven studies recruited patients presumed to have lower health literacy (based on their educational status) and reported conclusions about health literacy [52,56,67-71]. Three randomized trials compared lower health literacy or education groups to higher health literacy groups. Two Australian studies developed PtDAs for bowel cancer screening $[56,71]$, one specifically designed for a lower health literacy audience [56]. One U.S. study additionally addressed prostate cancer screening through a comparison "edutainment" PtDA and a paper PtDA [67]. All three of these PtDAs appear to have adhered to the IPDAS literacy criteria and included quantitative outcome data and explained technical terms. One PtDA was paper-based [71]; the remaining two used either audio or multi-media.

Two of three studies showed that PtDAs increased knowledge in samples presumed to have lower health literacy based on their educational status. Trevena et al. found a significant increase in knowledge in both lowerand highly-educated participants in the PtDA arm [71]. Smith et al. reported a $38 \%$ increase in knowledge and a $22 \%$ increase in informed choice (adequate knowledge and consistent attitudes and behavior) in lower education adults who received the literacy-sensitive PtDA compared with those who received standard information [56]. The third study-on prostate cancer screening-found no difference in knowledge between the "edutainment" and an audio-booklet presentation containing the same information [67]. However, the entertainment-based PtDA was associated with lower decisional conflict and greater selfadvocacy when compared to the audio booklet among "low health literacy" patients. No differences between were observed for "high health literacy" patients.

\section{Discussion}

Overall, our reviews suggest that patients with lower health literacy may be less able to use PtDAs effectively and to engage in shared decision making unless special attention has been paid to low health literacy in the PtDA development process. The reviews also indicate that patients with lower health literacy may be at greater need of support in decision making, given their higher levels of uncertainty and decisional regret, less involvement, and less patient-centered care. These findings suggest that attention to the needs of lower health literacy patients is required in PtDAs. Our reviews of the PtDA literature shows that health literacy has rarely been considered in the literature to date. However, in the small number of studies where the literacy needs of patients have been attended to, the results are encouraging.

Our reviews indicate that developers need to ensure they attend not only to issues of comprehension (functional health literacy), but also to values clarification and to the processes involved in the decision-making encounter itself (communicative and critical health literacy). If PtDAs are to be helpful in structuring and guiding decision making, they must address health literacy issues related to all of these processes. Because current evidence best supports improving the design and content of PtDAs-as summarized in Table 3-this should be a priority and will facilitate comprehension among lower health literacy patients.

The use of these strategies is recommended for the development of PtDAs for lower health literacy patients. However, intervention research relating to values clarification and the decision-making encounter are extremely limited, with almost no intervention studies available to guide PtDA developers. More research here is especially 
needed to understand potential differential effects of interventions by literacy level.

With regards to patient involvement, we note the consistent observation that patients with lower health literacy desire less involvement in decision making. We suggest that this may in part be a consequence of a lack of awareness that they can be involved and a lack of confidence in sharing the decision process with health care providers [72]. In patients with higher health literacy, desire for involvement has been found to increase when patients are shown the PtDA tools that are available [73]. Entwistle and colleagues emphasize the complexity of patients' desire and capacity for involvement in health decisions and suggest that using a trusted source, such as a health care provider, to make decisions (i.e., "intellectual outsourcing") can be an autonomyenhancing strategy for some patients, including patients who do not feel they have the capacity to make a shared decision [74,75]. Entwistle highlights relational approaches to understanding health decision making that offer broader understandings of how patient autonomy in health decision making and in shared decision making can be achieved. Here, more research is needed to understanding the meaning and implications of involvement with lower literacy groups.

From our reviews of the PtDA literature, only 3 out of 97 PtDA trials included adults with lower education or health literacy, or used PtDAs designed explicitly to address lower health literacy audiences. In $90 \%$ or more of the trials, the reading needs of the participants and the reading level of the PtDAs were not reported. A clear bottom line is that PtDAs are rarely developed with lower literacy populations in mind, despite the observations that in many developed countries only half the population has more than basic reading skills [9], and that health information developed for adults at a grade 8 reading level is widely accepted by more educated as well as less educated users [76,77]. However, in PtDA studies in which education and health literacy were addressed, results across literacy groups are positive, with increases in knowledge and in informed choice reported.

In addition to the principles identified in these reviews, others' reviews suggest strategies that may be useful when applied to PtDA development. For instance, we believe that particular principles based on the broader health literacy literature can be tentatively applied to the design, development, testing and implementation of PtDAs for lower health literacy patients [1]. See Table 9.

Until further evidence is available, PtDA developers may also turn to best practices materials for development and testing that have been outlined by literacy experts and several national organizations (see, for example, [78-84]).

\section{Principles for PtDA development and areas for further research}

The field must continue to push ahead with new research among lower health literacy populations. There are important deficits in the PtDA literature; much work is still needed to develop and test strategies to help adults with lower health literacy to gain key literacy skills, to engage in the values clarification process, and to be involved in doctor-patient communication. We propose that the most useful information in the field will result if PtDA developers do the following:

1. Use a measurable strategy to ensure that the language of the PtDA is written at a level that is understood by the majority of the target audience (e.g., Flesch-Kincaid, Simple Measure Of Gobbledegook (SMOG), Fry Readability Formula (or Fry Readability Graph), or other accepted approaches; see http://www. nlm.nih.gov/medlineplus/etr.html, Suitability Assessment

Table 9 Expert Opinion-Based Principles from the Broader Literature for Successful Health Literacy Interventions

\begin{tabular}{ll}
\hline \multicolumn{1}{c}{ Principles } & \multicolumn{1}{c}{ Rationale (based on broader health literacy literature) [1] } \\
\hline Use high intensity interventions & $\begin{array}{l}\text { Use multiple literacy-directed strategies to support knowledge acquisition and understanding. } \\
\text { For example, design PtDAs using plain language, simple numbers, and a range of visual and linguistic } \\
\text { techniques. Delivery of the PtDA requires multiple reinforcing contacts to support active decision-making. }\end{array}$ \\
$\begin{array}{ll}\text { Use theory-based interventions } \\
\text { when appropriate }\end{array}$ & $\begin{array}{l}\text { Theory can be used to maximize the impact of PtDAs. For instance, behavioral and communication theories } \\
\text { applied in PtDAs can motivate engagement with the PtDA, or, if appropriate, engagement in specific } \\
\text { behaviors. }\end{array}$ \\
\hline Pilot test before full implementation & $\begin{array}{l}\text { Pilot testing a PtDA involves examining the information needs and communication preferences of lower } \\
\text { literacy populations, and examining the whole process of decision making among lower health literacy } \\
\text { patients. }\end{array}$ \\
& $\begin{array}{l}\text { This means checking not only understanding of the language and content, but also whether the PtDA helps } \\
\text { users to clarify values, communicate with health professionals, and implement a decision. }\end{array}$ \\
\hline Increased emphasis on skill building & $\begin{array}{l}\text { PtDAs should be designed to help with skill building. This suggests that demonstrating and modeling values } \\
\text { clarification and physician interactions in PtDAs may improve outcomes among low literacy users of PtDAs. }\end{array}$ \\
\hline Delivery by a health professional & $\begin{array}{l}\text { Deliver PtDAs by a health professional (e.g., pharmacist, health educator, nurse, physician) rather than by non- } \\
\text { clinicians. This also suggests that delivery of PtDAs in the context of clinical care might result in the best } \\
\text { outcomes. }\end{array}$ \\
\hline
\end{tabular}


of Materials (SAM) or Systemic Functional Linguistics [85].

2. State how the PtDA accommodated health literacy or numeracy requirements identified in the population and whether good health literacy principles were followed [e.g [78-83]].

3. Recruit, where possible, adequate numbers of low health literacy / numeracy individuals to evaluate effectiveness in this population. If full inclusion is not possible, report results of pilot studies among lower health literacy patients.

4. In conjunction with point 3 , assess literacy / health literacy and/or numeracy levels in study samples by directly measuring functional health literacy and/or numeracy among a representative sample of the target sample of patients, using a recognized measure such as TOFHLA, REALM, or Newest Vital Signs (NVS).

5. Assess outcomes that have been shown to be or are postulated to be of specific concern for lower literacy patients.

Important research gaps in the field include a) the role of health literacy in the process of values clarification, $b$ ) the need to identify the characteristics of PtDAs that are universally acceptable and helpful, and c) the need to identify those characteristics that are particularly effective at enhancing shared decision making among people with lower health literacy/numeracy. Ultimately, this future research will contribute in important ways towards understanding the effects of PtDAs on health inequalities and towards ensuring that lower literacy/ numeracy groups are not disadvantaged.

\section{Limitations}

There are a number of limitations to our reviews of the decision-making literature. The decision for inclusion/ exclusion was based on only a single assessment of each article. Although the articles closest in subject to our reviews' purposes were assessed by two reviewers, it is possible that some relevant studies were missed. Other limitations include the inherent potential for publication bias, the diversity of measures used for similar outcomes, and the small number of physicians (despite adequate numbers of patients) that were included in studies of health literacy and communication. Indeed, many of the reviewed studies had small samples and larger studies are needed in future research. We also acknowledge there may be confounding and lack of control of relevant variables in some of the papers included in our reviews; however, we have presented the quality rating of our reviewed studies and indicated those with adjusted analyses. Although not a specific limitation of our reviews, one additional issue is that we excluded studies stratifying analyses by education. We made this choice because our search was not designed to pick up education as a proxy for literacy and we likely would have missed many relevant studies. It should be noted, however, that important information may be learned from such studies $[67,86]$. Furthermore, this field is growing quickly and we are already aware of new studies published since the study period $[87,88]$. While these studies support the conclusions in our reviews, it is possible that other new studies would provide new or different insights. Future updates will be important.

In our reviews of the PtDA literature, health literacy was not directly measured in any study. Proxy measures were used in three studies that reported having recruited individuals with unspecified deficits in education and health literacy. A limitation of our reviews is that we have not included the background articles that describe the development of PtDAs tested in the trials. Adding these may provide greater insight into how literacy was addressed. It does not, however, address the lack of attention to literacy in the trials and in identification of research questions. A related limitation is that we included only RCTs. Other studies of PtDAs that used different research designs may have included PtDAs that addressed low health literacy. We also note that there is now mixed evidence regarding the benefit of alternate media on improving outcomes for lower literacy patients, and so review criteria may need to be revised for future reviews [13].

\section{Conclusion}

Because lower health literacy groups have lower levels of knowledge and involvement in health care, and some of the poorest health outcomes, they may be considered a priority group for better support in health decision making. Yet little attention has been given to this group in the PtDA literature. To enable more equitable access to PtDA resources and shared decision making, developers of PtDAs need to ensure that tools are accessible to lower as well as higher health literacy patients, and that lower health literacy groups are better equipped and supported to utilize PtDAs. Evidence is available to improve written information for lower health literacy patients; this evidence needs to be used more widely in PtDA development. However, there is little evidence to guide values clarification and increasing patient involvement in the consultation for this group of patients. More research is needed in these domains, in particular, to facilitate shared decision making among patients from varying health literacy backgrounds.

\section{Additional material}

Additional file 1: Appendix 1: Review I: Overview of included studies

Additional file 2: Appendix 2: Review I: Relationships between Health Literacy and Values Clarity/Decision Confidence 
Additional file 3: Appendix 3: Review I: Relationship between Health Literacy and Selected Patient-Physician Communication Variables

Additional file 4: Appendix 4: Review I: Effect of Health Literacy Interventions on Decision-Making Outcomes

Additional file 5: Appendix 5: Review II: Further Details about Procedures and Coding of PtDA Trials

\section{List of abbreviations used}

NVS: Newest Vital Signs; PtDA: patient decision aid; RCTs: randomized controlled trials; REALM: Rapid Estimate of Adult Literacy in Medicine; SAM: Suitability Assessment of Materials; SMOG: Simple Measure Of Gobbledegook; TOFHLA: Test of Functional Health Literacy in Adults

\section{Competing interests}

Kirsten McCaffery and Marla Clayman have received research funding from the Informed Medical Decisions Foundation, a not-for-profit (501 (c)3) private foundation (http://www.informedmedicaldecisions.org). The Foundation develops content for patient education programs. The Foundation has an arrangement with a for-profit company, Health Dialog, to co-produce these programs. The programs are used as part of the decision support and disease management services Health Dialog provides to consumers through health care organizations and employers.

All other authors have no competing interests to declare.

\section{Authors' contributions}

KM and SLS drafted the manuscript with comments from MHR, DR, SKS and DN. All authors contributed to the drafting of the chapter on which the paper was based. SLS led the decision making review which involved MC, KM, SKS and MW. MHR and DR led the DA RCT review with input from KKB. DN, SKS and KM contributed to the theoretical framework for the paper. All authors read and approved the final manuscript.

\section{Acknowledgements}

We would like to thank Bob Volk and Hilary Llewellyn-Thomas for their guidance and support during the preparation of this manuscript. We would also like to thank the Agency for Healthcare Research and Quality for support of prior systematic reviews that made this work possible. We would like to thank the Cochrane Collaboration Patient Decision Aid Review team at the University of Ottawa for providing access to manuscripts contained in the published review and those pending review. Kirsten McCaffery is funded by a National Health and Medical Research Council Career Development Fellowship number 1029241.

\section{Declarations}

Publication of this supplement was partially funded by an unrestricted grant from the Informed Medical Decisions Foundation. The remaining costs were shared equally among the authors through a combination of institutional and personal funds. Administrative and editorial support for this supplement was also provided by The University of Texas MD Anderson Cancer Center. This article has been published as part of BMC Medical Informatics and Decision Making Volume 13 Supplement 2, 2013: The International Patient Decision Aid Standards (IPDAS) Collaboration's Quality Dimensions: Theoretical Rationales, Current Evidence, and Emerging Issues. The full contents of the supplement are available online at http://www. biomedcentral.com/bmcmedinformdecismak/supplements/13/S2

\section{Authors' details}

'Sydney School of Public Health, Sydney Medical School, Edward Ford Building (A27), The University of Sydney, NSW 2006, Australia. ${ }^{2}$ Center for Ethics and Humanities in the Life Sciences, College of Human Medicine, Michigan State University, East Fee Hall, 965 Fee Road Rm C-203, East Lansing, Michigan 48824, USA. ${ }^{3}$ Psychosocial Research Group, Prince of Wales Clinical School, Faculty of Medicine, University of New South Wales, Prince of Wales Hospital, Dickenson Building, Level 3, Randwick, NSW 2031, Australia. ${ }^{4}$ Office of the Vice-Chancellor, University of Southampton, University Road, Southampton SO17 1BJ, UK. ${ }^{5}$ Division of General Internal Medicine, Feinberg School of Medicine, Northwestern University, 750 North Lake Shore Drive, $10^{\text {th }}$ Floor, Chicago, Illinois 60611, USA. ${ }^{6}$ Division of
General Medicine and Clinical Epidemiology, The University of North Carolina at Chapel Hill, 5039 Old Clinic Building, CB\#7110, Chapel Hill, North Carolina 27599, USA.

Published: 29 November 2013

\section{References}

1. Berkman ND, Sheridan SL, Donahue KE, Halpern DJ, Crotty K: Low health literacy and health outcomes: an updated systematic review. Ann Intern Med 2011, 155:97-107.

2. McCaffery KJ, Smith S, Wolf MS: The challenge of shared decision making among adults with low literacy: a framework for research and development. Med Decis Making 2010, 30:35-44.

3. Elwyn G, O'Connor A, Stacey D, Volk R, Edwards A, Coulter A, the International Patient Decision Aids Standards C: Developing a quality criteria framework for patient decision aids: online international Delphi consensus process. BMJ 2006, 333:417.

4. Institute of Medicine: Health literacy: a prescription to end confusion. Washington, DC: National Academies Press; 2004.

5. US Department of Health and Human Services: Healthy people 2010: understanding and improving health. Washington DC; 2000.

6. Nutbeam D: Health Promotion Glossary. World Health Organization. Geneva: WHO/HPR/98.1; 1998.

7. Nutbeam D: Health literacy as a public health goal: a challenge for contemporary health education and communication strategies into the 21st century. Health Promot Int 2000, 15:259-267 [http://heapro. oxfordjournals.org/content/15/3/259.full].

8. Nutbeam D: Defining and measuring health literacy: what can we learn from literacy studies? Int J Public Health 2009, 54:303-305.

9. Kutner M, Greenberg E, J B: National Assessment of Adult Literacy (NAAL). A first look at the literacy of America's adults in the 21st century. [http:// nces.ed.gov/naal].

10. OECD: Learning a living: first results of the adult literacy and life skills survey. Catalogue no. 89-603-XWE: Statistics Canada Ottawa and Paris. Organisation for Economic Co-operation and Development; [http://www. statcan.gc.ca/].

11. DeWalt DA, Berkman ND, Sheridan S, Lohr KN, Pignone MP: Literacy and health outcomes: a systematic review of the literature. J Gen Intern Med 2004, 19:1228-1239.

12. Pignone M, DeWalt DA, Sheridan S, Berkman N, Lohr KN: Interventions to improve health outcomes for patients with low literacy. J Gen Intern Med 2005, 20:185-192.

13. Sheridan SL, Halpern DJ, Viera AJ, Donahue K, Berkman ND, Krotty KA: Interventions for individuals with low health literacy: a systematic review. J Health Commun 2011, 16(Suppl 3):30-54.

14. Williams MV, Davis T, Parker RM, Weiss BD: The role of health literacy in patient-physician communication. Fam Med 2002, 34:383-389.

15. Kinnersley P, Edwards A, Hood K, Ryan R, Prout H, Cadbury N, MacBeth F, Butow P, Butler $C$ : Interventions before consultations to help patients address their information needs by encouraging question asking: systematic review. BMJ 2008, 337:a485.

16. McCormack LA, Treiman K, Rupert D, Williams-Piehota P, Nadler E, Arora NK, Lawrence W, Street RL Jr:: Measuring patient-centered communication in cancer care: a literature review and the development of a systematic approach. Soc Sci Med 2011, 72:1085-1095.

17. Elwyn G, O'Connor AM, Bennett C, Newcombe RG, Politi M, Durand MA, Drake E, Joseph-Williams N, Khangura S, Saarimaki A, et al: Assessing the quality of decision support technologies using the International Patient Decision Aid Standards instrument (IPDASi). PLoS One 2009, 4:e4705.

18. Bryant MD, Schoenberg ED, Johnson TV, Goodman M, Owen-Smith A, Master VA: Multimedia version of a standard medical questionnaire improves patient understanding across all literacy levels. J Urol 2009, 182:1120-1125.

19. Galesic M, Garcia-Retamero R, Gigerenzer G: Using icon arrays to communicate medical risks: overcoming low numeracy. Health Psychol 2009, 28:210-216.

20. Galesic M, Gigerenzer G, Straubinger N: Natural frequencies help older adults and people with low numeracy to evaluate medical screening tests. Med Decis Making 2009, 29:368-371.

21. Garcia-Retamero R, Galesic M: Communicating treatment risk reduction to people with low numeracy skills: a cross-cultural comparison. Am J Public Health 2009, 99:2196-2202. 
22. Greene J, Peters E, Mertz C, Hibbard J: Comprehension and choice of a consumer-directed health plan: an experimental study. Am J Manag Care 2008, 14:369-376.

23. Meade CD, McKinney WP, Barnas GP: Educating patients with limited literacy skills: the effectiveness of printed and videotaped materials about colon cancer. Am J Public Health 1994, 84:119-121.

24. Murphy PW, Chesson AL, Walker L, Arnold CL, Chesson LM: Comparing the effectiveness of video and written material for improving knowledge among sleep disorders clinic patients with limited literacy skills. South Med J 2000, 93:297-304.

25. Peters E, Dieckmann N, Dixon A, Hibbard JH, Mertz CK: Less is more in presenting quality information to consumers. Med Care Res Rev 2007, 64:169-190.

26. Tait AR, Voepel-Lewis T, Zikmund-Fisher BJ, Fagerlin A: Presenting research risks and benefits to parents: does format matter? Anesth Analg 2010, 111:718-723.

27. Volandes $A E$, Paasche-Orlow MK, Barry MJ, Gillick MR, Minaker KL, Chang Y, Cook EF, Abbo ED, El-Jawahri A, Mitchell SL: Video decision support tool for advance care planning in dementia: randomised controlled trial. BMJ 2009, 338:b2159.

28. Wilson EAH, Park DC, Curtis LM, Cameron KA, Clayman ML, Makoul G, vom Eigen K, Wolf MS: Media and memory: the efficacy of video and print materials for promoting patient education about asthma. Patient Educ Couns 2010, 80:393-398.

29. Wright A, Whitwell S, Takeichi C, Hankins M, Marteau T: The impact of numeracy on reactions to different graphic risk presentation formats: an experimental analogue study. Br J Health Psychol 2009, 14:107-125.

30. Couper MP, Singer E, Levin CA, Fowler FJ Jr., Fagerlin A, Zikmund-Fisher BJ: Use of the internet and ratings of information sources for medical decisions: results from the DECISIONS survey. Med Decis Making 2010, 30(5 Suppl):106S-114S

31. Hawley ST, Janz NK, Hamilton A, Griggs JJ, Alderman AK, Mujahid M, Katz SJ: Latina patient perspectives about informed treatment decision making for breast cancer. Patient Educ Couns 2008, 73:363-370.

32. Sudore RL, Schillinger D, Knight SJ, Fried TR: Uncertainty about advance care planning treatment preferences among diverse older adults. $J$ Health Commun 2010, 15(Suppl 2):159-171.

33. Martin RW, Head AJ, Rene J, Swartz TJ, Fiechtner JJ, Mclntosh BA, HolmesRovner M: Patient decision-making related to antirheumatic drugs in rheumatoid arthritis: the importance of patient trust of physician. J Rheumatol 2008, 35:618-624.

34. Torres RY, Marks R: Relationships among health literacy, knowledge about hormone therapy, self-efficacy, and decision-making among postmenopausal health. J Health Commun 2009, 14:43-55.

35. Volandes AE, Barry MJ, Chang YC, Paasche-Orlow MK: Improving decision making at the end of life with video images. Med Decis Making 2010, 30:29-34.

36. DeWalt DA, Boone RS, Pignone MP: Literacy and its relationship with selfefficacy, trust, and participation in medical decision making. Am J Health Behav 2007, 31:S27-S35.

37. Lillie SE, Brewer NT, O'Neill SC, Morrill EF, Dees EC, Carey LA, Rimer BK: Retention and use of breast cancer recurrence risk information from genomic tests: the role of health literacy. Cancer Epidemiol Biomarkers Prev 2007, 16:249-255.

38. Mancuso CA, Rincon M: Asthma patients' assessments of health care and medical decision making: the role of health literacy. J Asthma 2006, 43:41-44.

39. Hibbard JH, Peters E, Dixon A, Tusler M: Consumer competencies and the use of comparative quality information: it isn't just about literacy. Med Care Res Rev 2007, 64:379-394.

40. Ishikawa H, Yano E, Fujimori S, Kinoshita M, Yamanouchi T, Yoshikawa M, Yamazaki $Y$, Teramoto T: Patient health literacy and patient-physician information exchange during a visit. Fam Pract 2009, 26:517-523.

41. Katz M, Jacobson T, Veledar E, Kripalani S: Patient literacy and questionasking behavior during the medical encounter: a mixed-methods analysis. J Gen Intern Med 2007, 22:782-786.

42. Arthur SA, Geiser HR, Arriola KRJ, Kripalani S: Health literacy and control in the medical encounter: a mixed-methods analysis. J Natl Med Assoc 2009, 101:677-683.

43. Schillinger D, Bindman A, Wang F, Stewart A, Piette J: Functional health literacy and the quality of physician-patient communication among diabetes patients. Patient Educ Couns 2004, 52:315-323.
44. Sudore RL, Landefeld CS, Perez-Stable EJ, Bibbins-Domingo K, Williams BA, Schillinger D: Unraveling the relationship between literacy, language proficiency, and patient-physician communication. Patient Educ Couns 2009, 75:398-402.

45. Wynia MK, Osborn CY: Health literacy and communication quality in health care organizations. J Health Commun 2010, 15:102-115.

46. Smith SG, Wolf MS, von Wagner C: Socioeconomic status, statistical confidence, and patient-provider communication: an analysis of the Health Information National Trends Survey (HINTS 2007). J Health Commun 2010, 15(Suppl 3):169-185.

47. Ciampa PJ, Osborn CY, Peterson NB, Rothman RL: Patient numeracy, perceptions of provider communication, and colorectal cancer screening utilization. J Health Commun 2010, 15(Suppl 3):157-168.

48. Shone LP, Conn KM, Sanders L, Halterman JS: The role of parent health literacy among urban children with persistent asthma. Patient Educ Couns 2009, 75:368-375.

49. Price-Haywood EG, Roth KG, Shelby K, Cooper LA: Cancer risk communication with low health literacy patients: a continuing medical education program. J Gen Intern Med 2010, 25:S126-S129.

50. Stacey D, Bennett CL, Barry MJ, Col NF, Eden KB, Holmes-Rovner M, Llewellyn-Thomas H, Lyddiatt A, Legare F, Thomson R: Decision aids for people facing health treatment or screening decisions. Cochrane Database Syst Rev 2011, , 10: CD001431.

51. Holmes-Rovner M, Kroll J, Rovner DR, Schmitt N, Rothert M, Padonu G, Talarczyk G: Patient decision support intervention: increased consistency with decision analytic models. Med Care 1999, 37:270-284

52. Oakley S, Walley T: A pilot study assessing the effectiveness of a decision aid on patient adherence with oral bisphosphonate medication. Pharm $J$ 2006, 276:536-538.

53. Rothert ML, Holmes-Rovner M, Rovner D, Kroll J, Breer L, Talarczyk G, Schmitt N, Padonu G, Wills C: An educational intervention as decision support for menopausal women. Res Nurs Health 1997, 20:377-387.

54. Schapira MM, Gilligan MA, McAuliffe T, Garmon G, Carnes M, Nattinger AB: Decision-making at menopause: $A$ randomized controlled trial of a computer-based hormone therapy decision-aid. Patient Educ Couns 2007, 67:100-107.

55. Ratanawongsa N, Zikmund-Fisher BJ, Couper MP, Van Hoewyk J, Powe NR: Race, ethnicity, and shared decision making for hyperlipidemia and hypertension treatment: the DECISIONS survey. Med Decis Making 2010, 30(5 Suppl):65S-76S.

56. Smith SK, Trevena L, Simpson JM, Barratt A, Nutbeam D, McCaffery KJ: A decision aid to support informed choices about bowel cancer screening among adults with low education: randomised controlled trial. BMJ 2010, 341:c5370

57. van Peperstraten A, Nelen W, Grol R, Zielhuis G, Adang E, Stalmeler P, Hermens R, Kremer J: The effect of a multifaceted empowerment strategy on decision making about the number of embryos transferred in in vitro fertilisation: randomised controlled trial. BMJ 2010, 341:C2501.

58. Evans $R$, Joseph-Williams $N$, Edwards $A$, Newcombe RG, Wright $P$, Kinnersley P, Griffiths J, Jones M, Williams J, Grol R, et al: Supporting informed decision making for prostate specific antigen (PSA) testing on the web: an online randomized controlled trial. J Med Internet Res 2010, 12:e27.

59. Fraenkel L, Rabidou N, Wittink D, Fried T: Improving informed decisionmaking for patients with knee pain. J Rheumatol 2007, 34:1894-1898.

60. Frosch DL, Bhatnagar $\mathrm{V}$, Tally S, Hamori CJ, Kaplan RM: Internet patient decision support: a randomized controlled trial comparing alternative approaches for men considering prostate cancer screening. Arch Intern Med 2008, 168:363-369.

61. Frosch DL, Kaplan RM, Felitti VJ: A randomized controlled trial comparing internet and video to facilitate patient education for men considering the prostate specific antigen test. J Gen Intern Med 2003, 18:781-787.

62. Krist $\mathrm{AH}$, Woolf $\mathrm{SH}$, Johnson RE, Kerns JW: Patient education on prostate cancer screening and involvement in decision making. Ann Fam Med 2007, 5:112-119.

63. Hoffman RM, Lewis CL, Pignone MP, Couper MP, Barry MJ, Elmore JG, Levin CA, Van Hoewyk J, Zikmund-Fisher BJ: Decision-making processes for breast, colorectal, and prostate cancer screening: the DECISIONS survey. Med Decis Making 2010, 30(Suppl 5):53S-64S.

64. Mathieu E, Barratt AL, McGeechan K, Davey HM, Howard K, Houssami N: Helping women make choices about mammography screening: an 
online randomized trial of a decision aid for 40-year-old women. Patient Educ Couns 2010, 81:63-72.

65. Ruffin MT, Fetters MD, Jimbo M: Preference-based electronic decision aid to promote colorectal cancer screening: results of a randomized controlled trial. Prev Med 2007, 45:267-273.

66. Vandemheen $\mathrm{K}, \mathrm{O}^{\prime}$ Connor A, Bell S, Freitag A, Bye P, Jeanneret A, Berthiaume Y, Brown N, Wilcox P, Ryan G, et al: Randomized trial of a decision aid for patients with cystic fibrosis considering lung transplantation. Am J Respir Crit Care Med 2009, 180:761-768.

67. Volk RJ, Jibaja-Weiss ML, Hawley ST, Kneuper S, Spann SJ, Miles BJ, Hyman DJ: Entertainment education for prostate cancer screening: a randomized trial among primary care patients with low health literacy. Patient Educ Couns 2008, 73:482-489.

68. Rovner DR, Wills CE, Bonham V, Williams G, Lillie J, Kelly-Blake K Williams MV, Holmes-Rovner M: Decision aids for benign prostatic hyperplasia: applicability across race and education. Med Decis Making 2004, 24:359-366.

69. Solberg LI, Asche SE, Sepucha K, Thygeson NM, Madden JE, Morrissey L, Kraemer KK, Anderson LH: Informed choice assistance for women making uterine fibroid treatment decisions: a practical clinical trial. Med Decis Making 2010, 30:444-452

70. Street RL, Voigt B, Geyer C, Manning T, Swanson GP: Increasing patient involvement in choosing treatment for early breast cancer. Cancer 1995, 76:2275-2285.

71. Trevena $L$, Irwig L, Barratt A: Randomized trial of a self-administered decision aid for colorectal cancer screening. J Med Screen 2008, 15:76-82.

72. Smith SK, Trevena L, Nutbeam D, Barratt A, McCaffery KJ: Information needs and preferences of low and high literacy consumers for decisions about colorectal cancer screening: utilizing a linguistic model. Health Expect 2008, 11:123-136.

73. van Tol-Geerdink JJ, Leer JW, van Lin EN, Schimmel EC, Huizenga $H$, van Daal WA, Stalmeier PF: Offering a treatment choice in the irradiation of prostate cancer leads to better informed and more active patients, without harm to well-being. Int I Radiat Oncol Biol Phys 2008, 70:442-448.

74. Entwistle VA, Carter SM, Trevena L, Flitcroft K, Irwig L, McCaffery K, Salkeld G: Communicating about screening. BMJ 2008, 337:a1591.

75. Entwistle VA, Carter SM, Cribb A, McCaffery K: Supporting patient autonomy: the importance of clinician-patient relationships. I Gen Intern Med 2010, 25:741-745.

76. Davis $\mathrm{TC}$, et al: Parent comprehension of polio vaccine information pamphlets. Pediatrics 1996, 97:804-810.

77. Kleimann S, Enlow B: Is plain language appropriate for well-educated and politically important people? Results of research with congressional correspondence. Clarity 2003, 50:4-10.

78. Develop Materials. [http://www.cdc.gov/healthliteracy/DevelopMaterials/]

79. Health Literacy Universal Precautions Toolkit. AHRQ Publication No. 100046-EF. [http://www.ahrq.gov/qual/literacy/healthliteracytoolkit.pdf].

80. DeWalt D, Callahan L, Hawk V, Broucksou K, Hink A, Rudd R, Brach C: Health Literacy Universal Precautions Toolkit. (Prepared by North Carolina Network Consortium, The Cecil G. Sheps Center for Health Services Research, The University of North Carolina at Chapel Hill, under Contract No. HHSA290200710014. AHRQ Publication No. 10-0046-EF). Rockville, MD: Agency for Healthcare Research and Quality; 2010 [http://www.cdc. gov/healthliteracy/pdf/Simply Put.pdf].

81. Federal plain language guidelines. [http://www.plainlanguage.gov/howto/ guidelines/bigdoc/fullbigdoc.pdf].

82. Home webpage. [http://www.cancer.gov/].

83. Health literacy studies: assessing and developing health materials. [http://www.hsph.harvard.edu/healthliteracy/practice/innovative-actions/ index.html].

84. Doak CC, Doak LG, Root JH: Teaching patients with low literacy skills. Philadelphia: J. B. Lippincott; 21996.

85. Clerehan R, Buchbinder R, Moodie J: A linguistic framework for assessing the quality of written patient information: its use in assessing methotrexate information for rheumatoid arthritis. Health Educ Res 2005 , 20:334-344.

86. Smith RA, Cokkinides V, Brawley OW: Cancer screening in the United States, 2008: a review of current American Cancer Society guidelines and cancer screening issues. CA Cancer J Clin 2008, 58:161-179.
87. Wilson EA, Makoul G, Bojarski EA, Bailey SC, Waite KR, Rapp DN, Baker DW, Wolf MS: Comparative analysis of print and multimedia health materials: a review of the literature. Patient Educ Couns 2012, 89:7-14.

88. Manganello JA, Clayman ML: The association of understanding of medical statistics with health information seeking and health provider interaction in a national sample of young adults. J Health Commun 2011, 16(Suppl 3):163-176.

doi:10.1186/1472-6947-13-S2-S10

Cite this article as: McCaffery et al:: Addressing health literacy in patient decision aids. BMC Medical Informatics and Decision Making 2013 13(Suppl 2):S10.

\section{Submit your next manuscript to BioMed Central and take full advantage of:}

- Convenient online submission

- Thorough peer review

- No space constraints or color figure charges

- Immediate publication on acceptance

- Inclusion in PubMed, CAS, Scopus and Google Scholar

- Research which is freely available for redistribution

Submit your manuscript at www.biomedcentral.com/submit
Ciomed Central 